\title{
Effect of self-heating on the processing quality of rapeseed
}

\author{
Marzena Gawrysiak-Witulska ${ }^{1}$, Aleksander Siger ${ }^{2}$, Magdalena Rudzińska ${ }^{1}$, Kinga Stuper-Szablewska ${ }^{3}$, \\ and Robert Rusinek ${ }^{4}$
}

\author{
${ }^{1}$ Institute of Food Technology, Poznań University of Life Sciences, Wojska Polskiego 28, 60-637 Poznań, Poland \\ ${ }^{2}$ Department of Biochemistry and Food Analysis, Poznań University of Life Sciences, Wojska Polskiego 28, 60-637 Poznań, Poland \\ ${ }^{3}$ Department of Chemistry, Poznań University of Life Sciences, Wojska Polskiego 75, 60-625 Poznań, Poland \\ ${ }^{4}$ Institute of Agrophysics, Polish Academy of Sciences, Doświadczalna 4, 20-290 Lublin, Poland
}

Received September 18, 2017; accepted January 31, 2018

\begin{abstract}
The paper concerns the effect of adverse thermal phenomena on the processing quality of rapeseed. A measurement station was developed for the study, composed of a model cylindrical silo with a capacity of $3.85 \mathrm{~m}^{3}$, which was filled with seeds of winter rape cv. Suzy (2.5 t). In the conducted experiment, the silo was filled with three layers of seeds, the bottom layer with a moisture content of $7 \%$, the middle layer with a moisture content of $12.7 \%$, and the top layer with a moisture content of $7 \%$. The experiment was carried out with temperature and humidity sensors in the vertical and horizontal axes, placed in a distance of $0.15 \mathrm{~m}$ from one another. The increase in temperature in the intergranular space measured during the self-heating phenomenon can be divided into two stages: I-slow (up to approx. $150 \mathrm{~h}$ ) and II - significant (from $150 \mathrm{~h}, 2-3^{\circ} \mathrm{C}$ per day). As a result of the development of the self-heating phenomenon, the processing quality of rapeseed deteriorated. Indeed, under increased temperature the quality changes were so significant that they rendered the seeds unfit for any kind of consumption purposes.

Keywords: rapeseed, self-heating, acid value, bioactive compounds, ergosterol
\end{abstract}

\section{INTRODUCTION}

Self-heating is a common cause of the deterioration of freshly harvested seeds. The reason for this phenomenon may be high moisture content and temperature of the seeds harvested (Reuss and Pratt, 2001). This phenomenon may also be related to the excessive metabolic activity of insects living in the crops (Arbogast et al., 2004). Self-heating is a destructive phenomenon influencing the quality of the material. This is unfortunately rather common in storage practice. The process leads to losses of dry matter, as well as the growth of microbes and mould, the feeding of insects, and increased amounts of free fatty acids (Pronyk et al., 2006). Increased rapeseed contamination with mould fungi also causes several adverse changes in the processing quali-

*Corresponding author e-mail: aleksander.siger@op.pl ty of this raw material and obtained products. Moreover, it poses a risk of rapeseed contamination with the secondary metabolites of these microorganisms, i.e. mycotoxins, that exhibit toxic effects on humans and animals (Hussein and Brasel, 2001). The degree of microbiological contamination in plant materials is typically determined using a method proposed by Seitz et al. (1977), which involves the assay of ergosterol (ERG). Ergosterol is the main sterol found in the cell membranes of most mould fungi (Zhao et al., 2005).

Rapeseed oil is considered to be one of the most valuable vegetable fats. It is a rich source of mono- and polyenic acids (Sanders, 2000), as well as natural oxidation inhibitors, i.e. tocopherols, phenolic compounds and phytosterols (Gawrysiak-Witulska et al., 2009, 2012). An increase in temperature may result in the degradation of these valuable compounds and the formation of oxidised phytosterol derivatives, which are known to have cytotoxic and carcenogenic properties (Gawrysiak-Witulska et al., 2012; Ryan et al., 2009).

The physical consequences of the self-heating phenomenon include the formation of an area with increased temperature, lumping of seeds, and the obstructed outflow of the material from the container. The ability to detect this phenomenon depends on the thermal conductivity of bulk materials. According to the studies by Bilanski and Fisher (1976), rapeseed has poor thermal conductivity, from 0.1082 to $0.1608 \mathrm{~W} \mathrm{~m}^{-1} \mathrm{~K}^{-1}$, which is an advantage on the one hand, because pre-cooled seeds hold their pre-set temperature for a long time, while on the other, it is a drawback due to their low heat emission. The poor migration of heat increases the dynamics of the self-heating phenomenon and impedes the process of locating and detecting it.

(C) 2018 Institute of Agrophysics, Polish Academy of Sciences 
The aim of the conducted analyses was to simulate the phenomenon of rapeseed self-heating on the pilot plant scale and to determine changes in the processing and microbiological rapeseed quality during this phenomenon.

\section{MATERIALS AND METHODS}

For the purposes of this study, a measuring station was prepared, composed of a model cylindrical silo of $3.85 \mathrm{~m}^{3}$, which was filled with $2.5 \mathrm{t}$ of winter rape cv. seeds Suzy (Fig. 1). A cylindrical container of $1.7 \mathrm{~m}$ in height and $1.7 \mathrm{~m}$ in diameter was made of steel sheeting and covered with plywood. A snail conveyor was used to fill the container, which, after the completion of the experiment, and prior to being fit under the container, further enabled the collection of seeds pouring out from the outlet. The container was filled centrally, directly from the snail conveyor, with sensors placed in the $\mathrm{x}$ and $\mathrm{y}$ directions, at every $0.15 \mathrm{~m}$. Each sensor measured the temperature and relative humidity of the air in intergranular spaces, with the data sent to the managing module via a transmission main of the 1-wire type. All data - sensor numbers, temperature values, humidity, measurement number, additional information were archived in the non-volatile memory of the device. Consequently, the content of the memory was read with the use of a setup application compatible with popular operating systems, and the data was saved in a file that could be converted to the '*.xls' format, and worked with, or put into diagrams, formulae, etc. using commonly accessible software.

During the test, the sensor network was adjusted in such a manner as to place the intersection of the $\mathrm{x}$ and $\mathrm{y}$ axes at the focal point of the model container (in which the most dynamic progression of the phenomenon was expected to occur). In the experiment, the silo was filled with three seed layers, each $0.5 \mathrm{~m}$ high: the first one at the bottom with a moisture content of $7 \%$ (w.b.), the second with a moisture content of $12.7 \%$, and the last, top layer, with a moisture content of $7 \%$ (w.b.). During the test, from the geometric

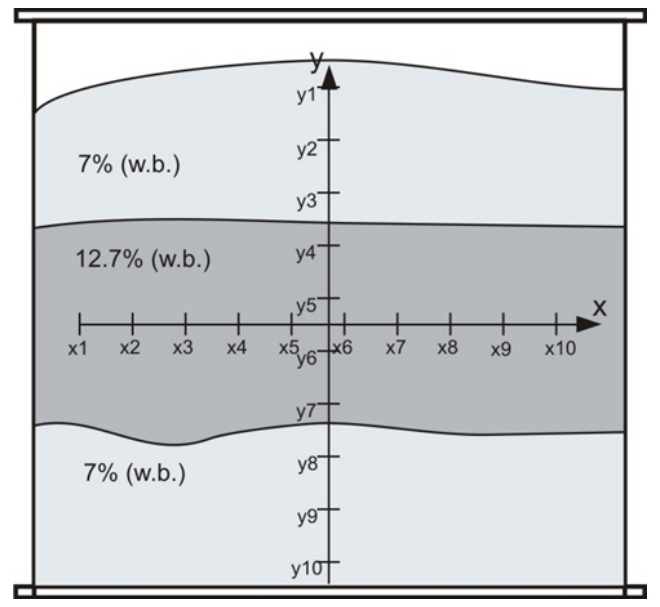

Fig. 1. Model silo: y1, y2, y3, ... y10 - vertical sensors, x1, x2, x3, ... x10 - horizontal sensors, distance between sensors $=15 \mathrm{~cm}$. centre of the rapeseed layer with a moisture content of $12.7 \%$ (w.b.), a $0.5 \mathrm{~kg}$ sample portion of seeds was collected every day and frozen for later analyses of changes in processing and microbiological quality. Samples were collected from the geometric centre of the silo, since based on previous experiments, it was established that this was the site where the temperature rose the fastest and where the greatest changes in processing quality were expected.

The test showed the phenomenon of seed self-heating, the progression of the phenomenon being recorded by a set of sensors. Indeed, in the final stage of the test, several days before its termination, the temperature in the self-heating area was rising in an almost linear progression by about $2-3^{\circ} \mathrm{C}$ per day. Due to the unpredictability of the process, the experiment was stopped at a temperature of $50^{\circ} \mathrm{C}$.

From the samples taken during the experiment, seeds taken from the field after 6 days of storage (the end of the slow temperature increase) and after 13 days (the end of the experiment) were collected for analyses of their microbiological and processing quality.

The oil from the seeds was extracted using the Folch procedure (Folch et al., 1957). Seeds were crushed and homogenised with chloroform:methanol $(2: 1 \mathrm{v} / \mathrm{v})$. The solvent was washed with water, vortexed for several seconds and then centrifuged $(2000 \mathrm{rpm})$ to separate the two phases. The chloroform layer was collected and evaporated under vacuum using a Buchi R 215 rotoevaporator (Büchi Labortechnik AG, Flawil, Switzerland).

Acid value was determined according to the AOCS Official Method Cd 3d-63 (2007). The acid value was expressed as the amount of $\mathrm{KOH}$ (in milligrams) necessary to neutralise free fatty acids contained in $1 \mathrm{~g}$ of oil.

Phytosterol contents were determined by the AOCS Official Method Ch 6-91 (1997), as modified by Ciftci et al. (2011). In brief, extracted oils (50 mg) were saponified with $1 \mathrm{M} \mathrm{KOH}$ in methanol for $18 \mathrm{~h}$ at room temperature, then water was added and unsaponifiables were extracted three times with hexane/methyl tert-butyl ether $(1: 1, \mathrm{v} / \mathrm{v})$. The solvent was evaporated under a stream of nitrogen. Dry residues were dissolved in $0.2 \mathrm{ml}$ pyridine and silylated with $0.8 \mathrm{~mL}$ of Sylon BTZ (Supelco, Bellefonte, PA, USA). Derivatives of the phytosterols were separated on an HP 6890 gas chromatograph equipped with a DB-35MS capillary column $(25 \mathrm{~m} \times 0.20 \mathrm{~mm} ; 0.33 \mu \mathrm{m}$; J\&W Scientific, Folsom, CA). A sample was injected in a splitless mode. Column temperature was held at $100^{\circ} \mathrm{C}$ for $5 \mathrm{~min}$, then programmed to 250 at $25^{\circ} \mathrm{C} \mathrm{min}^{-1}$, held for $1 \mathrm{~min}$, then further programmed to 290 at $3^{\circ} \mathrm{C} \mathrm{min}^{-1}$ and held for $20 \mathrm{~min}$. Detector temperature was set at $300^{\circ} \mathrm{C}$. Hydrogen was used as a carrier gas at a flow rate of $1.5 \mathrm{ml} \mathrm{min}^{-1}$. As the internal standard, $5 \alpha$-cholestane was used for sterol quantification. Phytosterols were identified by comparing the retention data of standards, and this was confirmed using an Agilent Technologies 7890A GC apparatus coupled to a 5975C VL MSD Triple-Axis Detector after separation on 
a DB-5 capillary column ( $30 \mathrm{~m}$ x $0.2 \mathrm{~mm}, 0.32 \mathrm{~mm}$; J\&W). Helium was used as a carrier gas at a flow rate of $0.6 \mathrm{ml}$ $\mathrm{min}^{-1}$. All mass spectra were recorded using the electronimpact ionisation mode at $70 \mathrm{eV}$ and a scanning mass in the range of 100-650 Da. The ion source was held at $200^{\circ} \mathrm{C}$ and the injector at $300^{\circ} \mathrm{C}$. A combination of the NIST Mass Spectra Library and a laboratory sterol spectra library were used for identification.

Tocochromanols and PC-8 contents were determined by Gawrysiak-Witulska et al. (2011) Seed samples ( $2 \mathrm{~g})$ were saponified using $60 \% \mathrm{KOH}(2 \mathrm{ml})$, ethanol $(20 \mathrm{ml})$ and pyrogallol $(0.5 \mathrm{~g})$. Saponification was carried out at the ethanol boiling point temperature $\left(78^{\circ} \mathrm{C}\right)$ for $30 \mathrm{~min}$. After saponification, unsaponifiable substances were extracted using $50 \mathrm{ml} n$-hexane/ethyl acetate $(90: 10 \mathrm{v} / \mathrm{v})$. Subsequently, $100 \mu \mathrm{l}$ of the organic layer (unsaponifiable) were collected for high-performance liquid chromatography (Waters 600, Milford, MA, USA). A LiChrosorb Si60 column $(250 \times 4.6 \mathrm{~mm} ; 5 \mu \mathrm{m})$ and a LiChrospher Si60 precolumn were used. The mobile phase consisted of $n$-hexane and 1,4-dioxane $(97: 3 \mathrm{v} / \mathrm{v})$. Flow rate was $1.5 \mathrm{ml} \mathrm{min}^{-1}$. The fluorometric detector (Waters 474, Milford, MA, USA) worked at an excitation at $295 \mathrm{~nm}$ and an emission at 330 $\mathrm{nm}$. Tocopherols $(\alpha-\mathrm{T}, \beta-\mathrm{T}, \gamma-\mathrm{T}, \delta$-T) were identified by comparing retention times and concentrations were calculated by comparing the area values with values from exterior standard tocopherols (Merck, Darmstadt, Germany).

The defatted rapeseed methanol extracts were prepared according to the method described by Siger et al. (2012). The total phenolic content was determined using the FolinCiocalteu method and expressed in $\mathrm{mg}$ of sinapic acid equivalents per $100 \mathrm{~g}$ of the sample (Czubiński et al., 2012). From the methanolic extracts, free phenolic acid fractions were isolated according to the previous method (Dwiecki et al., 2012). The Chromabond ${ }^{\circledR}$ System (Macherey-Nagle, Germany) was applied, together with the SPE Bakerbond $\mathrm{spe}^{\mathrm{TM}}$ columns filled with a quaternary amine $(500 \mathrm{mg})$ in order to isolate the free phenolic acid fraction.

Polar phenolic compounds were identified and quantified using high-performance liquid chromatography (HPLC - Waters, Milford, MA) equipped with an XBridge ${ }^{\mathrm{TM}} \mathrm{C} 18$ reversed-phase column $(4.6 \times 100 \mathrm{~mm} ; 3.5 \mu \mathrm{m})$ (Waters, Milford, MA). A gradient program was used, combining solvent A (acetonitrile: water 50:50 v/v) and solvent B (water adjusted to $\mathrm{pH} 2.7$ with ortho-phosphoric acid) as follows: $0-50 \% \mathrm{~A}(60 \mathrm{~min}), 50-0 \% \mathrm{~A}(9 \mathrm{~min})$. The flow rate was $1.0 \mathrm{ml} \mathrm{min}^{-1}$. The injection volume was $10 \mu \mathrm{l}$, while the column temperature was maintained at $20^{\circ} \mathrm{C}$. The signal was monitored at 200-600 $\mathrm{nm}$ via diode array detector (DAD) (UV-VIS Waters, Milford, MA). The quantitative determination of phenolic compounds was carried out by comparing retention times and diode array spectral characteristics with the corresponding standards (Siger et al., 2013).
Samples were analysed for the presence of ergosterol according to Perkowski et al. (2008). In brief, samples of $100 \mathrm{mg}$ were placed into culture tubes, suspended in methanol, treated with $2 \mathrm{M}$ aqueous $\mathrm{NaOH}$ and sealed tightly. The samples were then irradiated $(370 \mathrm{~W})$ for $20 \mathrm{~s}$, after $5 \mathrm{~min}$ for an additional $20 \mathrm{~s}$ and extracted with pentane $(3 \times 4 \mathrm{ml})$ within the culture tubes. The combined pentane extracts were evaporated to dryness in a gentle stream of high purity nitrogen. Prior to analysis, samples were dissolved in $4 \mathrm{ml}$ of methanol, filtered through $13 \mathrm{~mm}$ syringe filters with a $0.5 \mu \mathrm{m}$ pore diameter, evaporated to dryness in a stream of nitrogen and dissolved in $1 \mathrm{ml}$ of methanol. The prepared samples were analysed by HPLC. Separation was run on a $150 \mathrm{~mm}$ (length) x $3.9 \mathrm{~mm}$ (diameter) Nova Pak C-18.4 $\mu \mathrm{m}$ particle size column and eluted with methanol/ acetonitrile (90:10) at a flow rate of $0.6 \mathrm{ml} / \mathrm{min}$. ERG was detected with a Waters 486 Tunable Absorbance Detector set at $282 \mathrm{~nm}$. The estimation of ERG was performed by comparing peak areas with those of an external standard ( $>95 \%$, Aldrich, Milwaukee, USA) or by co-injection with a standard. The detection level was $0.01 \mathrm{mg} \mathrm{kg}^{-1}$.

The results are presented as means \pm standard deviation from three replicates of each experiment. A p-value $<0.05$ was applied to denote significant differences between mean values determined by the analysis of variance with the assistance of Statistica 10.0 (StatSoft Inc., Tulsa, OK) software.

\section{RESULTS AND DISCUSSION}

The increase in temperature in the intergranular space measured during the process may be divided into two stages: I - slow (up to approx. $150 \mathrm{~h}$ ) and II - significant (from $150 \mathrm{~h}, 2-3^{\circ} \mathrm{C}$ per day) (Fig. 2). The most active area, where the phenomenon evolved most dynamically, was near the geometric centre of the seed layer with $12.7 \%$ moisture content (w.b.). The area was monitored by $\mathrm{x} 4, \mathrm{x} 5, \mathrm{x} 6, \mathrm{x} 7$ sensors along the horizontal axis and $\mathrm{y} 5, \mathrm{y} 6, \mathrm{y} 7$ and $\mathrm{y} 8$ sensors along the vertical axis. The proximity of the container wall facilitated more effective heat emission from the seed mass, which was recorded by $\mathrm{x} 1$ and $\mathrm{x} 10$ and, to a lesser extent, $\mathrm{x} 2$ and $\mathrm{x} 9$ sensors. Most probably, some of the heat was absorbed by the tank wall (due to the high thermal conductivity of steel). However, the interface between the seeds and the wall in this area was a kind of a vertical channel, which facilitated convective lifting of the heated air particles. However, as it turned out after emptying the tank, the more effective heat removal was not sufficient to protect the seeds from spoilage. The whole layer with a moisture content of $12.7 \%$ (w.b.) along the tank's horizontal axis was similarly lumped.

The recorded changes in the humidity of the intergranular spaces during rapeseed self-heating, compared to the temperature changes, were rather minor (Fig. 3). Similar 

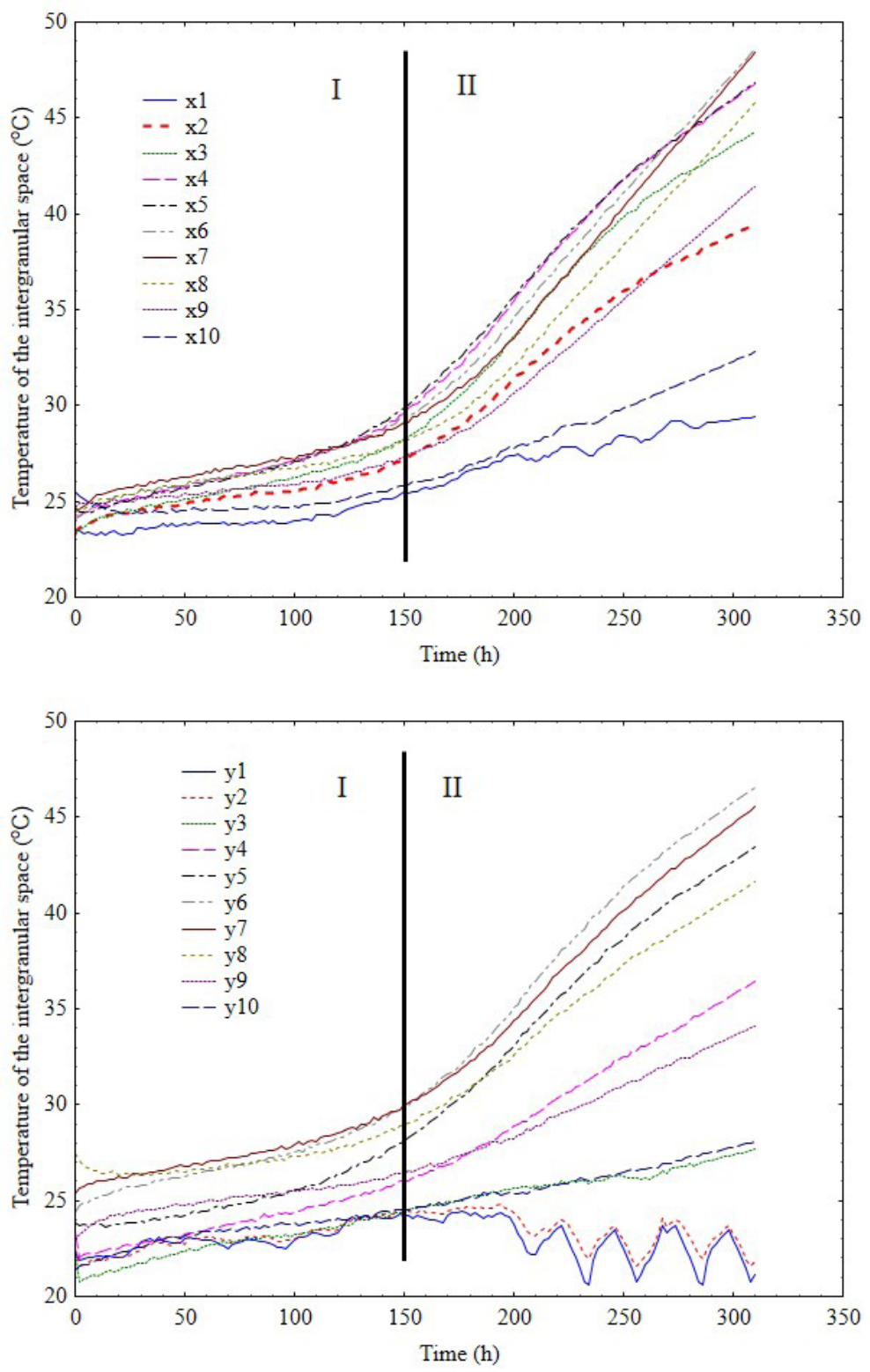

Fig. 2. Experimental distribution of temperatures along the $\mathrm{x}(\mathrm{a})$ and $\mathrm{y}(\mathrm{b})$ axes.

results, but for moisture content, of wheat grain bulk-stored for 15 months in a metal silo in Canada, were obtained by Jian et al. (2009).

In all samples, the acid value and contents of phytosterols, tocopherols, phenolic acids and ergosterol were recorded.

Acid values of rape harvested from the field and stored in the silo are shown in Table 1. The AV value in the harvested rapeseed samples was $1.27 \mathrm{mg} \mathrm{KOH} \mathrm{g}^{-1}$ of oil. Storing seeds with an increased humidity resulted in an increase in the acid value. After 6 days, it was $2.77 \mathrm{mg} \mathrm{KOH} \mathrm{g}^{-1}$ (a 118\% increase) and $64.64 \mathrm{mg} \mathrm{KOH} \mathrm{g}^{-1}$ (a $5100 \%$ increase) after the experiment termination. According to the PN-90 R-66151, the AV in rapeseeds for the food industry should be under $3 \mathrm{mg} \mathrm{KOH} \mathrm{g}{ }^{-1}$. The results may indicate that during rapeseed self-heating, in stage I of the slow increase in temperature, seeds retain their processing usefulness, whereas seeds subjected to a significant increase in temperature (stage II) are no longer suitable for the food industry. Gawrysiak-Witulska et al. (2011) showed that after 18-day storage of seeds with 10 and $12.5 \%$ moisture contents at 25 and $30^{\circ} \mathrm{C}$, the acid value did not exceed $3 \mathrm{mg}$ $\mathrm{KOH} \mathrm{g} \mathrm{g}^{-1}$. In turn, in seeds with $15.5 \%$ moisture content, stored under identical conditions, the acid value exceeded that level considerably. Appelqvist and Loof (1972) state that good-quality seeds with a moisture content of $7 \%$ may be stored for 3 years, showing only a slight increase in the content of free fatty acids, while in mouldy seeds stored under identical conditions, the amount of free fatty acids increased to $18 \%$. 

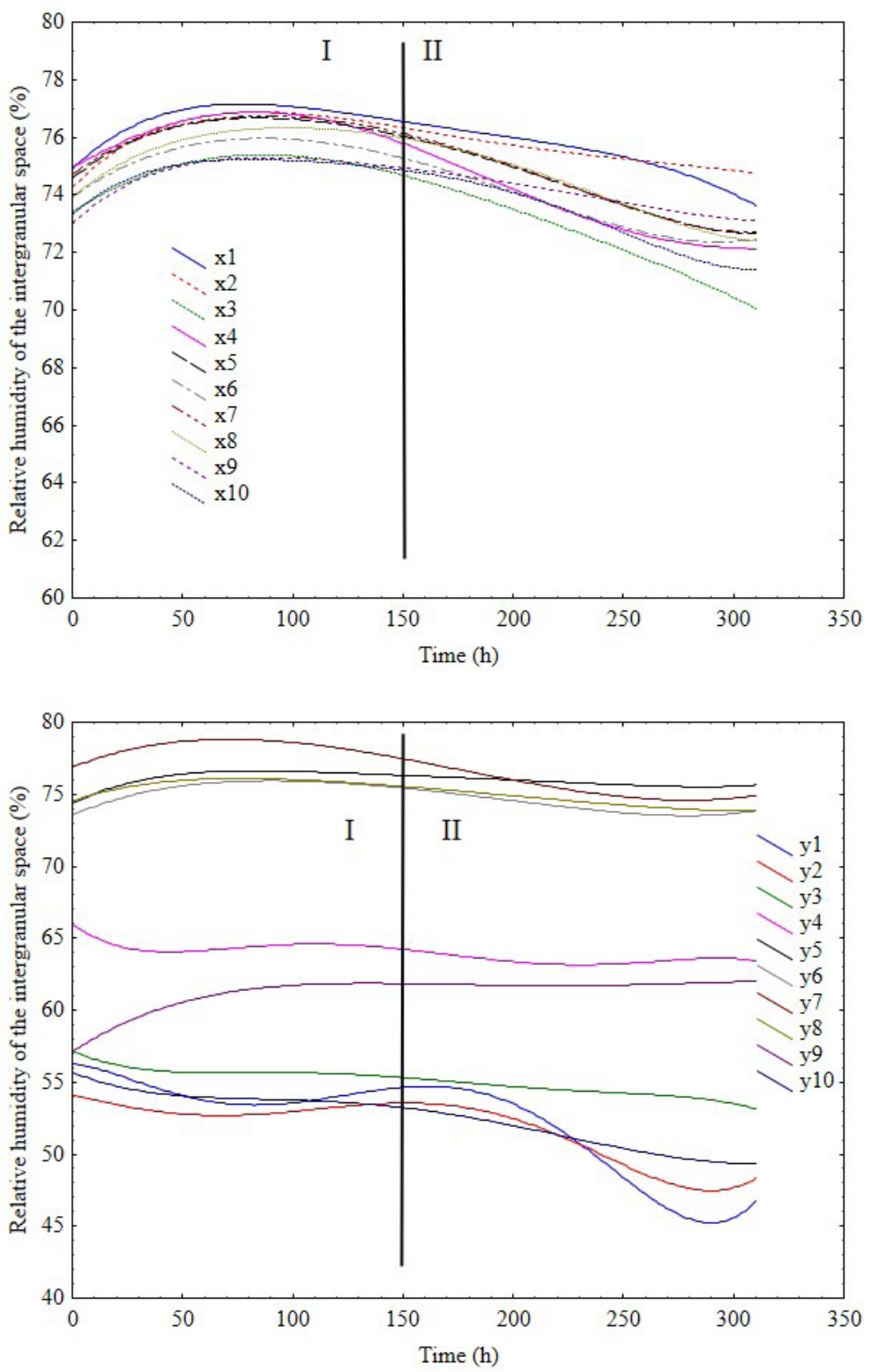

Fig. 3. Experimental distribution of changes in the relative humidity in the intergranular spaces along the $x$ (a) and $y$ (b) axes.

Appropriate rapeseed storage has a significant effect on the contents of bioactive compounds (phytosterols, tocopherols, phenolic compounds), important from the nutritional and storage point of view, and manifested in the quality of produced oil. In rapeseed following harvesting, the overall content of phytosterol was $6178 \mathrm{mg} \mathrm{kg}^{-1}$ (Table 1). The dominating sterol was $\beta$-sitosterol, which constituted $47 \%$ (2949 $\left.\mathrm{mg} \mathrm{kg}^{-1}\right)$ of the overall content of sterols. Brassicasterol, characteristic of crucifer plants, in the oil extracted from seeds accounted for $9.3 \%\left(580 \mathrm{mg} \mathrm{kg}^{-1}\right)$ of all sterols. The content of campesterol was $2270 \mathrm{mg} \mathrm{kg}^{-1}$, whereas that of stigmasterol $114 \mathrm{mg} \mathrm{kg}^{-1}$ of seeds. Studies by Vlahakis and Hazebroek (2000) showed that apart from the cultivar, the content of phytosterols in rapeseed oil is influenced by seed moisture contents, harvest and storage conditions. In seed samples of three black-seeded cultivars investigated by Gawrysiak-Witulska et al. (2012), the total content of phytosterols ranged from 4095 to $4398 \mu \mathrm{g} \mathrm{g}^{-1}$ seeds. The conducted experiment showed that with the occurrence of the self-heating phenomenon, a decrease in the overall sterol content takes place. After stage I of the slow temperature increase, losses in the amount of sterols were $10 \%\left(5567 \mathrm{mg} \mathrm{kg}^{-1}\right)$, while in the later stage, losses increased to $22 \%$ (4845 $\mathrm{mg} \mathrm{kg}^{-1}$ ). During inappropriate rapeseed storage, Gawrysiak-Witulska and Rudzińska (2012) demonstrated a decrease in the total phytosterol content, while the rate of these changes depended on both the seed moisture content and the temperature during storage. In seeds with a moisture content of $12.5 \%$, stored at $25^{\circ} \mathrm{C}$, losses of total sterol contents after 18 days amounted 
Table 1. Acid value, the content of phytosterols, tocopherols, PC-8, phenolic compounds, and ergosterol in samples of seeds

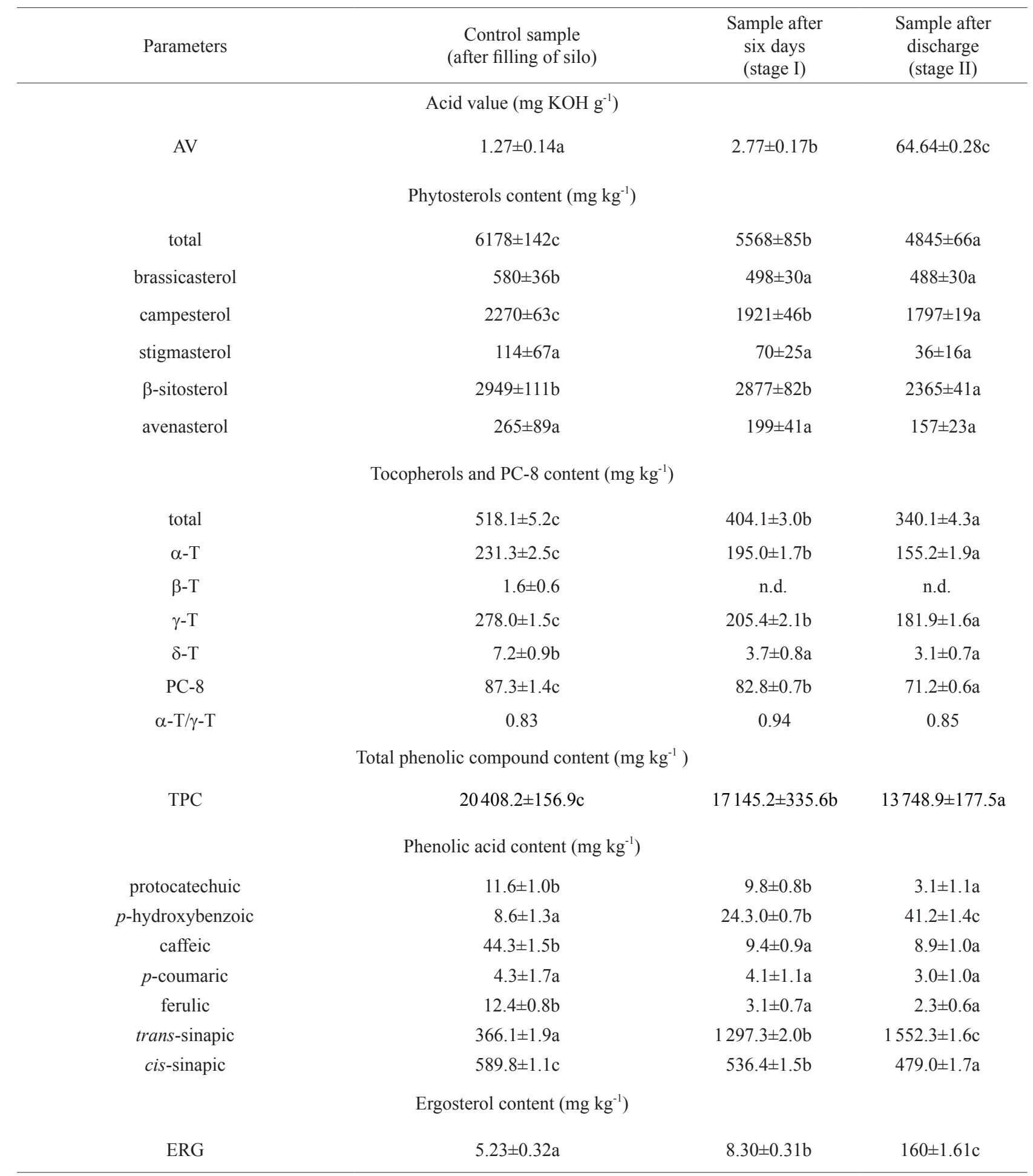

*Values (means $\pm \mathrm{SD}$ ) bearing different are statistically significantly different $(\mathrm{p}<0.05)$.

to $12 \%$, while in seeds stored at $30^{\circ} \mathrm{C}$, it was $16 \%$. Much greater phytosterol losses were recorded for seeds with a moisture content of $15.5 \%$. Storage of such moist seeds for 18 days at $25^{\circ} \mathrm{C}$ resulted in a $24 \%$ loss of sterols, whereas at $30^{\circ} \mathrm{C}$, the loss was as high as $58 \%$.
Stigmasterol and avenasterol are the sterols with the greatest degradation rate. Their losses during stage I were 38 and $25 \%$, respectively, whereas during stage II, they increased to 69 and $41 \%$. Losses of brassicasterol and campesterol during stage I were similar and amounted to 
$15-16 \%$, while for sitosterol, it was $3 \%$. During stage II, the losses increased to $16-21 \%$. In their earlier experiments, Gawrysiak-Witulska and Rudzińska (2012) noted that the storage of seeds with $12.5 \%$ moisture content for 18 days resulted in the greatest losses of stigmasterol $\left(17 \%\right.$ at $25^{\circ} \mathrm{C}$, $27 \%$ at $30^{\circ} \mathrm{C}$, respectively). In addition, research conducted by Rudzińska et al. (2006) during 12 months' storage of rapeseed at a moisture content of $7 \%$ (w.b.) at $20^{\circ} \mathrm{C}$ showed a $13 \%$ loss in phytosterols. As it is evident by our results, such losses during self-heating may already have taken place after stage I of the slow temperature increase.

The overall content of tocopherol in the rapeseed intended for storage was $518.1 \mathrm{mg} \mathrm{kg}^{-1}$ (Table 1). The dominating tocopherol was a $\gamma$-T homologue $\left(278.0 \mathrm{mg} \mathrm{kg}^{-1}\right)$, which constituted $54 \%$ of the overall content of tocopherols. The content of the $\alpha$-T homologue was $231.3 \mathrm{mg} \mathrm{kg}^{-1}$ $(45 \%)$, while that of $\beta-\mathrm{T}$ and $\delta$-T in the examined seeds was 1.6 and $7.2 \mathrm{mg} \mathrm{kg}^{-1}$, respectively. According to Marwede et al. (2004), in rape, the dominating homologs are $\gamma-\mathrm{T}(64 \%)$ and $\alpha-\mathrm{T}(35 \%)$, while $\beta$-T and $\delta$-T constitute no more than $1 \%$ of the content. As noted by the above-mentioned authors, the $\alpha$-T to $\gamma$-T ratio in rapeseed is within the range of 0.54 and 1.70. Experiments conducted by GawrysiakWitulska et al. (2011) confirmed this dependence. In the seeds sampled for storage, the $\alpha-\mathrm{T} / \gamma$-T ratio was 0.83 .

The conducted tests showed that during seed storage, the overall content of tocopherols decrease when the self-heating phenomenon takes place. After 6 days of storage, the overall tocopherol content in the stored rapeseed dropped by $23 \%$ ( $\left.401.1 \mathrm{mg} \mathrm{kg}^{-1}\right)$, while after 13 days, this figure was $35 \%$ (340.1 $\mathrm{mg} \mathrm{kg}^{-1}$ ) in relation to the control sample.

The initial content of the $\alpha-T$ homologue was $231.3 \mathrm{mg}$ $\mathrm{kg}^{-1}$. During the first six days of the experiment, its content dropped by $27 \%$ (195 $\mathrm{mg} \mathrm{kg}^{-1}$ ), and during further storage, by $35 \%\left(155.2 \mathrm{mg} \mathrm{kg}^{-1}\right)$. The $\gamma$-T homologue underwent considerably higher degradation during the conducted experiment. During stage I of temperature increase, its content decreased by $49 \%\left(205.4 \mathrm{mg} \mathrm{kg}^{-1}\right)$, while during stage II, the decrease was at $58 \%\left(181.9 \mathrm{mg} \mathrm{kg}^{-1}\right)$ in relation to the control sample. However, it must be stressed that during stage I of temperature increase in the examined deposit, the degradation of the $\gamma$-T homologue occurred faster than the degradation of $\alpha-T$. It engendered an increase in the $\alpha-T / \gamma-T$ ratio from 0.83 to 0.94 . In stage II, in a significant increase of temperature, the value of the $\alpha-\mathrm{T} / \gamma-\mathrm{T}$ ratio dropped to 0.85 , which means that during this period the degradation of $\alpha$-T progressed faster than that of $\gamma$-T. According to Gawrysiak-Witulska et al. (2009), 12-month storage of seeds with a moisture content of $7 \%$ (w.b.), but at $10^{\circ} \mathrm{C}$, caused a $23-30 \%$ loss of these compounds. Furthermore, Goffman and Möllers (2000) investigated changes in tocopherol contents in intact rapeseeds during storage at 5,20 and $40^{\circ} \mathrm{C}$ and observed losses of tocopherol contents only at a temperature of $40^{\circ} \mathrm{C}$. Gawrysiak-Witulska et al. (2016), during seed storage for 18 days under conditions simulating commercial silo environment, showed that moisture content has the greatest effect on losses of total tocopherol contents, as well as those of the $\alpha-T$ and $\gamma$-T homologues, followed by temperature, while pressure had only a slight effect. Our recorded research results also showed that for seeds with greater moisture contents (13 and $16 \%$ ), an increase in storage temperature from 25 to $30^{\circ} \mathrm{C}$ causes a more substantial loss of tocopherols than an increase in temperature from 30 to $35^{\circ} \mathrm{C}$.

Seed storage also caused a loss in PC-8. During six days of seed storage, the level of this homologue decreased by $6 \%$, whereas after 13 days, this figure increased by a further $5 \%$. The conducted experiment indicates that self-heating sharply accelerates the loss of tocopherols and PC-8. Although after the completion of stage I of temperature increase the seeds could be used for consumption purposes, the loss of tocopherols corresponded to losses of these compounds during one-year seed storage under appropriate conditions.

In the control sample, the content of total phenolic compounds in general amounted to $20408.2 \mathrm{mg} \mathrm{kg}^{-1}$ (Table 1). The experiment involving self-heating of rapeseed showed that this process significantly decreases their content. During stage I of storage, the total phenolic content dropped in general by $16 \%\left(17145.2 \mathrm{mg} \mathrm{kg}^{-1}\right)$. A fast growth in temperature during stage II of rapeseed storage caused a further decrease of total phenolic contents by an additional 16\% (13748.9 $\left.\mathrm{mg} \mathrm{kg}^{-1}\right)$.

When discussing the content of phenolic compounds, we need to remember that their content may be dependent on the solvent applied during extraction. In these analyses, the level of phenolic compounds was consistent with the results reported by Cai and Arntfield (2001) and Khattab et al. (2010). The aforementioned authors, when applying an aqueous methanol solution in the extraction process in ground rapeseeds, obtained a total phenolic content of $22900 \mathrm{mg} \mathrm{kg}^{-1}$.

Changes in contents of free phenolic acids in tested rapeseed samples are presented in Table 1 . The dominating phenolic acids were trans-sinapic acid and cis-sinapic acid. During seed storage, a drop in protocatechuic acid, caffeic acid, p-coumaric acid, ferulic acid and cis-sinapic acid was recorded. In turn, a significant increase in transsinapic and p-hydroxybenzoic acid was recorded. Herein, an increase in trans-sinapic acid by $250 \%$ (from 366.1 to $1297.3 \mathrm{mg} \mathrm{kg}^{-1}$ ) was recorded in stage I and by an additional $70 \%$ in stage II (to $1552.3 \mathrm{mg} \mathrm{kg}^{-1}$ ) (Table 1). In the case of p-hydroxybenzoic acid, an increase was recorded in its content by approx. $180 \%$, both in stages I and II of seed storage.

When comparing phenolic contents in seeds of rape (Brassica napus L.) with those in other oil crops, it was found that their content is 10-fold greater (Naczk et al., 1998). Kozlowska et al. (1983) reported that the main polar 
phenolic compound present in rapeseed was sinapic acid, the content of which was estimated at over $70 \%$ of the total content of free phenolic acids. Khattab et al. (2010) found sinapic acid content in rapeseed crude extract within the range of 9 to $59 \mathrm{mg} 100 \mathrm{~g} \mathrm{~g}^{-1}$, whereas in pressed cakes, it ranged from 29 to $44 \mathrm{mg} 100 \mathrm{~g}^{-1}$ and from 32 to $41 \mathrm{mg} 100 \mathrm{~g}^{-1}$ in meals, without any differentiation of the determined isomers. Phenolic compounds in rapeseeds are mostly found in the bound form (esterified or in the form of glycosides). They are primarily derivatives of sinapic acid (Siger et al., 2013). There are no data in available literature concerning the contents of phenolic compounds in rapeseeds during their storage under inappropriate conditions in the silo.

Changes in the contents of native antioxidants are affected by various types of biochemical processes, the intensity of which depends on storage conditions. According to Bewley et al. (2013), metabolic/biochemical processes do not occur below approx. $70 \%$ RH. Thus, this RH level is indicated as the approximate point of reference for division between 'dry' and 'wet' processes. Oxidative and peroxidative processes are responsible for dry seed damage. Through lipid peroxidation, these free radicals cause, either directly or indirectly, four types of cellular damage: mitochondrial dysfunction, enzyme inactivation, membrane perturbations, and genetic damage. So, the amount of antioxidants in seeds might reduce the incidence of cellular damage due to free radical assault during seed storage. On the other hand, the presence of solvent water tends to quench free radical mechanisms and enable antioxidant mechanisms to be effective. Thus, damage due to free radicals and reactive oxygen species (ROS) is most prevalent in dry seeds or in the lower moisture content range of wet seeds. At RH between 70 and $90 \%$, some enzyme activities can be detected (at very low rates) and substratelevel respiration may be detectable at the high end of this range. Active physiological processes associated with turgor, growth, and germination only occur above $99 \% \mathrm{RH}$. Within the $70-90 \%$ range, as observed in the tested seeds, hydrolytic processes are initiated due to the availability of free water. This also results in the reduced contents of individual bioactive compounds acting as native antioxidants (Bewley et al., 2013). Self-oxidation of lipids may be the primary cause for the deterioration of seed quality at moisture content below 6\%. At higher seed moisture content, lipid peroxidation may also be caused by the activity of hydrolytic oxidative enzymes such as lipoxygenase, the activity of which increases with an increase in water content. Lipoxygenases may also contribute to cell degradation through the modification of cell membrane composition. Two primary pathways for lipoxygenase activity have been described in higher plants, with the fatty acid hydroperoxides as the intermediate products (Loiseau et al., 2001). One of the pathways leads to the formation of traumatic acid, a compound that may be involved in plant cell wound response and volatile C6-aldehydes and C6-alcohols - shown to be correlated with seed deterioration (Wilson and McDonald, 1986). The other pathway leads to the formation of jasmonic acid, a compound playing a regulatory role in plant cells (Sembdner and Parthier, 1993). Lipases constitute another important group of enzymes having a potential effect on the recorded results. They catalyse the hydrolysis of water insoluble triacylglycerols. This reaction occurs at the interphase of water with lipids, and leads to the formation of fatty acids, diacylglycerols, monoacylglycerols and glycerol. Lipases also catalyse hydrolysis of water soluble short-chain esters of carboxylic acids; however, the rate of this reaction is very slow. Optimum $\mathrm{pH}$ of the reaction for plant lipases is 4.7-5.0, while the effective temperature ranges from 35 and $37^{\circ} \mathrm{C}$. These temperatures correspond to the temperatures recorded in our experiment (Pahoja and Sethar, 2002). Seeds contain a complex antioxidant defence system in order to protect against the consequences of reactive oxygen species. One system is based on enzymes neutralising activated oxygen forms such as peroxide dismutase, catalase and glutathione peroxidase (Gille and Joenje, 1991). The other defence system comprises nonenzymatic compounds, the so-called antioxidants, such as tocopherols, phenols and ascorbate. These compounds can destroy free radicals and stop their propagation, reducing damage to the seed. However, at low water contents in dry seeds, enzymatic mechanisms to regenerate antioxidants are inoperative, so it is expected that they would eventually be exhausted, enabling ROS activity to become damaging (Bewley et al., 2013).

In our study, we showed a change in the contents (generally a decrease) of individual homologues of tocopherols or phenolic compounds. In their study, Wilson et al. (1995) investigated the effect of fungal damage on seed composition and quality of soybeans. In their experiment, graded samples of the cv. Centennial soybean were dried to $10 \%$ moisture and blended on a proportional weight basis to derive a series of treatments from 0 to $80 \%$ fungal damage. They found no quantitative changes in the contents of native tocopherols in moulded soy seeds. In contrast, they showed that at the moment when the presence of pathogenic fungi caused an approx. 50\% reduction of total polar lipids, a significant increase in unidentified tocopherols was detected. It was presumed that those compounds represented the tocoquinones and tocol dimers which could contribute to the intensified oil colours in fungus-damaged soybean oil.

As far as phenolic compunds are concerned, in our study, we determined the contents of free phenolic acids. It needs to be stressed here that free phenolic acids account for only several percent of the total pool of phenolic compounds in rape seeds, with sinapine found in the greatest amounts. Among the various minor sinapate esters, sinapine constitutes the main phenolic component in seeds (Baumert et al., 2005). The possible physiological or ecological role of these seed-specific esters is still unknown. 
However, sinapine might function as a storage vehicle for the readily available supply of the most hygroscopic choline. During seed germination, sinapine is hydrolysed by an esterase activity. In the young seedlings, the released sinapate is reesterifed via sinapoylglucose to sinapoylmalate and a portion of free choline feeds into phosphatidylcholine biosynthesis (Milkowski et al., 2004). It is the hydrolytic processes that are mainly responsible for the increase in the contents of free phenolic acids. In their study, Rodriguez et al. (2005) showed that during post-harvest storage, asparagus experienced a general increase in ferulic acid monomers and dimers that affected every section of both the green and white spears. The storage of asparagus spears $\left(21^{\circ} \mathrm{C}\right.$ for 3 days) resulted in a considerable increase in phenolic acids (at least three-fold) in each section, particularly in the lower section, which was accompanied by an increase in the proportion of diferulic acid moieties in the mid and lower sections. When investigating phenolic compounds in white mustard seed, Liu et al. (2005) showed changes during the traditional stir-baked processing, especially after $15 \mathrm{~min}$, whereby p-hydroxybenzoic acid was formed. In brassicaceous plants, sinapic acid is converted into a broad spectrum of O-ester conjugates. These abundant soluble sinapic acid esters reflect a well-known metabolic network and are produced at different stages of plant development. The accumulation of these sinapic acid esters and soluble phenylpropanoids also provides protection against ultraviolet (UV)-B stress and is involved in the defensive response to pathogens such as Verticillium longisporum in Arabidopsis (Bi et al., 2017). In plants, abscisic acid is the primary regulator of growth and stress response. Recent studies suggest that phenylpropanoid metabolism plays an important role in the response to ABA. It is possible, therefore, that phenolics affect plant growth and development by inhibiting ABA synthesis and signaling processes (Bi et al., 2017). A study by Bouchereau et al. (1992) showed sequential structural changes in sinapic acid conjugates during germination and the early stages of seedling development of rape. Sinapine (sinapoylcholine), which is the major sinapoyl-conjugate stored in the seeds, is totally broken down within 7 days. The high increase in the contents of free sinapic acid may suggest increased enzymatic activity in the tested seeds. Sinapine esterase is the main enzyme degrading sinapine to free sinapic acid, and its effective temperature falls within the range of $25-40^{\circ} \mathrm{C}$, with the optimum at $35^{\circ} \mathrm{C}$ (Schomburg and Salzmann, 1991). The high increase in the contents of sinapic acid may also be a response to stress caused by rapid fungal growth. Simple phenolic compounds, such as methoxy and hydroxy benzoic acid and cinnamic acids, are commonly formed in decaying plant residues. Phenolic acids may supply alternative carbon sources to certain diazotrophs and may additionally serve as precursors for the synthesis of phenolic lipids. Secondary metabolites play important roles either as local or systemic resistance factors in protecting plants against various pathogens (Mandal et al., 2010).
The concentration of ergosterol in rapeseed after harvest amounted to $5.23 \mathrm{mg} \mathrm{kg}^{-1}$ (Table 1). The results indicate high microbiological contamination of seeds after harvest. As reported by Maupetit et al. (1993), the normal concentration of ergosterol in rape seed is $0-7.1 \mathrm{mg} \mathrm{kg}^{-1}$. For healthy seeds, Müler and Schwadorf (1990), as well as Maupetit et al. (1993), proposed a range of ergosterol concentration of 1-9 mg kg-1. According to Schnürer and Jansson (1992), the maximum ergosterol concentration in cereal intended for human consumption should not exceed $3 \mathrm{mg} \mathrm{kg}^{-1}$. In the conducted experiment, during stage I of seed storage, the concentration of ergosterol increased to $8.30 \mathrm{mg} \mathrm{kg}^{-1}$. This demonstrates the growth of mould fungi; nevertheless, visually, the seeds showed no signs of mould, and they were healthy according to the level proposed by Müler and Schwadorf (1990). During stage II, on rapeseed, mould fungi which coalesced completely could be observed on seed surface. Furthermore, the very strong mould fungi contamination of the material was confirmed by a very high content of ergosterol $\left(160 \mathrm{mg} \mathrm{kg}^{-1}\right)$. Magan et al. (1993) indicated that growth of fungi and their biodeterioration activity were dependent on the interactions between various fungal species. They stated that fungi isolated from rape seeds produce enzymes responsible for the degradation of rape seeds or rapeseed oil. In turn, a study by Janda et al. (2016) showed that optimal growth conditions for fungi are not always identical to those for lipase biosynthesis. Meanwhile, Sathya et al. (2009) claimed that while humidity and air temperature are the primary abiotic factors responsible for the deterioration of seed quality, humidity plays the most important role, while elevated temperature plays a secondary role in this process. Skiba et al. (2005) reported that an increase in temperature from 15 to $25^{\circ} \mathrm{C}$ results in a four-fold increase in biochemical intensity of these processes. Moreover, it is the increase in humidity from 7 to $9 \%$ that causes an eight-fold increase in the intensity of the processes. What is more, a study by Gawrysiak-Witulska et al. (2016) on the losses of the total tocopherol content, showed that moisture had the greatest impact. This was followed by temperature, while pressure had a slight effect.

\section{CONCLUSIONS}

1. The intensity of biological and chemical processes occurring in rapeseed depends on the storage conditions. The optimum moisture content in seeds intended for long-term storage should be 7\% (w.b). Storing seeds with increased moisture content leads to an increase in lipase activity - first native, then microbiological, which causes an increase in the quantity of free fatty acids. The oxidation and degradation of these compounds reduces the value of oil for consumption substantially. The experiment conducted in this study involving the self-heating of the rapeseed bed showed significant changes in the processing 
and microbiological quality of seeds, both during stage I - involving a slow temperature increase, and during stage II - involving a rapid temperature increase.

2. In stage I, a slower growth of AV and ergosterol was recorded in relation to stage II, whereas the degradation of biologically active compounds, such as plant sterols and phenol compounds in general, was comparable during stages I and II. In the case of tocopherols, a two-fold greater loss of these compounds was recorded during stage I in relation to stage II. Moreover, a detailed analysis of phenolic acids showed a significant growth in sinapic acid content during stage I, with a simultaneous drop in the low molecular derivative of this acid.

3. The increase in sinapic and $p$-hydroxybenzoic acids may result from the protective properties of phenol compounds against biotic stress - in this case, the growth of mould fungi. The increase in sinapic acid content results from the drop in its low molecular derivative and probably from the hydrolysis of sinapine - a sinapic acid ester with choline, while the increase in $p$-hydroxybenzoic acid level may result from the hydrolysis of polyphenolic compounds.

4. The process of rapeseed self-heating is a complex physico-chemical phenomenon. It seems that laboratory testing and the modelling of experiments only in terms of heat transfer are not sufficient. The recorded dynamics of the phenomenon indicate the occurrence of two self-heating stages: a slow increase in temperature and relative humidity in intergranular spaces; and an accelerated increase in temperature along with a slight increase, followed by a decrease, in relative humidity.

5. As a result of the progressing self-heating, the quality of rapeseed deteriorated. On the other hand, during the stage involving a slow temperature increase, quality changes were not considerable enough to render the seeds unfit for processing. It was only under increased temperature that the quality changes were so significant as to render the seeds unfit for any type consumption purposes.

Conflict of interest: The Authors do not declare conflict of interest.

\section{REFERENCES}

AOCS Official Method Cd 3d-63, Acid value, 2007. Official Method and Recommended Practices of the American Oil Chemists' Society, 5th ed. American Oil Chemists Society, USA.

AOCS Official Method Ch 6-91, 1997. Determination of the composition of the sterol fraction of animal and vegetable oils and fats by TLC and capillary GLC.

Appelqvist L. and Loof B., 1972. Post-harvest handling and storage of rapeseed. In: Rapeseed (Eds L. Appelqvist, R. Ohlson). Elsevier, Amsterdam.

Arbogast R.T., Weaver D.K., Kendra P.E., and Chini S.R., 2004. Temperature variation in stored maize and its effect on capture of beetles in grain probe traps. J. Stored Prod. Res., 40, 135-150.
Baumert A., Milkowski C., Schmidt J., Nimtz M., Wray V. and Strack D., 2005. Formation of a complex pattern of sinapate esters in Brassica napus seeds, catalysed by enzymes of a serine carboxypeptidase-like acyltransferase family. Phytochemistry, 66, 1334-1345.

Bewley J.D., Bradford K.J., Hilhorst H.W.M., and Nonogaki H., 2013. Seeds. Physiology of development, germination and dormancy. Springer Science+Business Media, LLC.

Bi B., Tang J., Han S., Guo J., and Miao Y., 2017. Sinapic acid or its derivatives interfere with abscisic acid homeostasis during Arabidopsis thaliana seed germination. BMC Plant Biol., 17, 2-12.

Bilanski W.K. and Fisher D.R., 1976. Thermal Conductivity of Rapeseed. Trans. ASAE, 19, 788-791.

Bouchereau A., Hamelin J., Renard M., and Larher F., 1992. Structural changes in sinapic acid conjugates during seedling development of rape. Plant Physiol. Biochem., 30, 467-475.

Cai R. and Arntfield S.D., 2001. A rapid high-performance liquid chromatographic method for the determination of sinapine and sinapic acid in canola seed and meal. J. Am. Oil Chem. Soc., 78, 903-910.

Ciftci O.N., Przybylski R., Rudzińska M., and Acharya S., 2011. Characterization of fenugreek (Trigonella foenumgraecum) seed lipids. J. Am. Oil Chem. Soc., 88, 1603-1610.

Czubinski J., Dwiecki K., Siger A., Lampart-Szczapa E., and Nogala-Kalucka M., 2012. Interactions between Lupinus angustifolius seeds lipoxygenase and native phenolic compouds in the model system. Eur. Food Res. Technol., 235, 67-73.

Dwiecki K., Siger A., Czubinski J., Nogala-Kalucka M., and Lampart-Szczapa E., 2012. The interactions between rapeseed lipoxygenase and native polyphenolic compounds in the model system. J. Am. Oil Chem. Soc., 89, 379-387.

Folch J., Lees M., and Stanley G.H.S., 1957. A simple method for the isolation and purification of total lipids from animal tissue. J. Biol. Chem., 726, 497-509.

Gawrysiak-Wituska M. and Rudzińska M., 2012. Degradation of phytosterols during near-ambient drying of rapeseeds in a thick immobile layer. J. Am. Oil Chem. Soc., 89, 1681-1689.

Gawrysiak-Witulska M., Rudzińska M., Wawrzyniak J., and Siger A., 2012. The effect of temperature and moisture content of stored rapeseed on the phytosterol degradation rate. J. Am. Oil Chem. Soc., 89, 1673-1679.

Gawrysiak-Witulska M., Siger A., and Nogala-Kalucka M., 2009. Degradation of tocopherols during near-ambient rapeseed drying. J. Food Lipid, 16, 524-539.

Gawrysiak-Witulska M., Siger A., and Rusinek R., 2016. Degradation of tocopherols during rapeseed storage in simulated conditions of industrial silos. Int. Agrophys., 30, 39-45.

Gawrysiak-Witulska M., Siger A., Wawrzyniak J., and Nogala-Kałucka M., 2011. Changes in tocochromanol content in seeds of Brassica napus L. during adverse conditions of storage. J. Am. Oil Chem. Soc., 88, 1379-1385.

Gille J.J.P. and Joenje H., 1991. Biological significance of oxygen toxicity: An introduction. In: Membrane Lipid Oxidation (Ed. C. Vigo-Pelfrey). Boca Raton, FL, CRC Press. 
Goffman F.D. and Möllers C., 2000. Changes in tocopherol and plastochromanol-8 contents in seeds and oil of oilseed rape (Brassica napus L.) during storage as influenced by temperature and air oxygen. J. Agric. Food Chem., 48, 16051609.

Hussein H.S. and Brasel J.M., 2001. Toxicity, metabolism, and impact of mycotoxins on humans and animals. Toxicol., 167, 101-134.

Janda K., Markowska-Szczupak A., and Ulfig K., 2016. The effect of water activity and temperature on the growth and lipolytic activity of Penicillium chrysogenum (thom) and Eurotium herbariorum (wigg.) strains. Folia Pomer. Univ. Technol. Stetin. Agric. Aliment. Pisc., Zootech., 328, 85-96.

Jian F., White N.D.G., and Jayas D.S., 2009. Temperature fluctuations and moisture migration in wheat stored for 15 months in a metal silo in Canada. J. Stored Prod. Res., 45, 82-90.

Khattab R., Eskin M., Aliani M., and Thiyam U., 2010. Determination of sinapic acid derivatives in canola extracts using high-performance liquid chromatography. J. Am. Oil Chem. Soc., 87, 147-155.

Kozlowska H., Zadernowski R., and Sosulski F., 1983. Phenolic acid in oilseed flours. Nahrung/Food, 27, 449-453.

Liu L., Zhou H., Sun S., Wang Q., and Li G., 2005. The effects of Chinese traditional processing method on components in semen Sinapis albae. Am. J. Biochem. Biotechnol., 1, 64-68.

Loiseau J., Benoit L.V., Macherel M.H., and Deunff Y.L., 2001. Seed lipoxygenases: Occurrence and functions. Seed Sci. Res., 11, 199-211.

Magan N., Jenkins N.E., and Howarth J., 1993. Lipolytic activity and degradation of rapeseed oil and rapeseed by spoilage fungi. Int. J. Food Microbiol., 19, 217-227.

Mandal S.M., Chakraborty D., and Dey S., 2010. Phenolic acids act as signaling molecules in plant-microbe symbioses. Plant Sign. Behav., 5, 359-368.

Marwede V., Schierholt A., Mollers C., and Becker H.C., 2004. Genotype $\mathrm{x}$ environment interactions and heritability of tocopherol contents in canola. Crop Sci., 44, 728-731.

Maupetit P., Gatel F., Cahagnier B., Botorel G., Charlier M., Collet B., Dauvillier P., Laffiteau J., and Roux G., 1993. Quantitative estimation of fungal infestation of feedstuffs by determining ergosterol content. 44th Annual Meeting of the EAAP. Aaugust 16-19, Comm. Animal Nutrittion Aarhus Denmark.

Milkowski C., Baumert A., Schmidt D., Nehlin L., and Strack D., 2004. Molecular regulation of sinapate ester metabolism in Brassica napus: expression of genes, properties of the encoded proteins and correlation of enzyme activities with metabolite accumulation. Plant J., 38, 80-92.

Mueller H-M. and Schwadorf K., 1990. Ergosterol and fungal count in cereal by-products. J. Anim. Physiol. Anim. Nutr., 64, 215-219.

Naczk M., Amarowicz R., Sulivan A., and Shahidi F., 1998. Current research developments on polyphenolics of rapeseed/canola: a review. Food Chem., 62, 489-502.

Pahoja M.V. and Sethar M.A., 2002. A review of enzymatic properties of lipase in plants, animals and microorganisms. Pak. J. Appl. Sci., 2, 474-484.
Perkowski J., Buśko M., Stuper K., Kostecki M., Matysiak A., and Szwajkowska-Michałek L., 2008. Concentration of ergosterol in small-grained naturally contaminated and inoculated cereals. Biologia, 63, 542-547.

Pronyk C., Abramson D., Muir W.E., and White N.D.G., 2006. Correlation of total ergosterol levels in stored canola with fungal deterioration. J. Stored Prod. Res., 42, 162-172.

Reuss R. and Pratt S., 2001. Accumulation of carbon monoxide and carbon dioxide in stored canola. J. Stored Prod. Res., 37, 23-34.

Rodriguez R., Jaramillo S., Guillen R., and Jimenez A., 2005. Cell wall phenolics of white and green asparagus. J. Sci. Food Agric., 85, 971-978.

Rudzińska M., Jeleń H., Nogala-Kałucka M., and GawrysiakWitulska M., 2006. The influence of storage time and drying temperature on sterols content in seeds of rapeseed. Oilseed Crops, 27, 302-312.

Ryan E., McCarthy F.O., Maguire A.R., and O'Brien N.M., 2009. Phytosterol oxidation products: Their formation, occurrence and biological effect. Food Rev. Int., 25, 157-174.

Sanders A.B.T., 2000. Polyunsaturated fatty acids in the food chain in Europe. Am. J. Clin. Nutr., 71, 176-178.

Sathya G., Jayas D.S., and White N.D.G., 2009. Safe storage guidelines for canola as the seeds slowly dry. Biosyst. Eng. 51, 329-338.

Schnürer J. and Jansson A., 1992. Ergosterol levels and mould colony forming units in Swdish grain of food and feed grade. Acta Agric. Scand. Sect. B, 42, 240-245.

Schomburg D. and Salzmann M., 1991. Enzyme handbook. Class 3: Hydrolases. Springer-Verlab Berlin Heidelberg.

Seitz L.M., Mohr H.E., Burroughs R., and Sauer D.B., 1977. Ergosterol as an indicator of fungal invasion in grains. Cereal Chem., 54, 1207-1217.

Sembdner G. and Parthier B., 1993. The biochemistry and the physiological and molecular actions of jasmonates. Ann. Rev. Plant Physiol. Plant Mol Biol., 44, 569-589.

Siger A., Czubiński J., Dwiecki K., Kachlicki P., and NogalaKałucka M., 2013. Identification and antioxidant activity of sinapic acid derivatives in Brassica napus L. seed meal extracts. Eur. J. Lipid Sci. Techol., 115, 1130-1138.

Siger A., Czubinski J., Kachlicki P., Dwiecki K., LampartSzczapa E., and Nogala-Kalucka M., 2012. Antioxidant activity and phenolics content in three lupin species. J. Food Comp. Anal., 25, 190-197.

Skiba K., Szwed G., and Tys J., 2005. Changes in the quality features of rapeseeds during storage. Acta Agrophysica, 6, 785-794.

Vlahakis C. and Hazebroek J., 2000. Phytosterol accumulation in canola, sunflower, and soybean oils: effects of genetics, planting location, and temperature. J. Am. Oil Chem. Soc., 77, 49-53.

Wilson D.O. and McDonald M.B., 1986. A convenient volatile aldehyde assay for measuring seed vigour. Seed Sci. Technol.,14, 259-268.

Wilson R.F., Novitzky W.P., and Fenner G.P., 1995. Effect of fungal damage on seed composition and quality of soybeans. J. Am. Oil Chem. Soc., 72,1425-1429.

Zhao X. R., Lin Q., and Brookes P.C., 2005. Does soil ergosterol concentration provide a reliable estimate of soil fungal biomass? Soil Biol. Biochem., 37, 311-317. 